\title{
Symptom Remission and Specific Resistance of Pepper Plants After Infection by Pepper golden mosaic virus
}

\author{
Jimena Carrillo-Tripp, Edmundo Lozoya-Gloria, and Rafael F. Rivera-Bustamante
}

Departamento de Ingeniería Genética, Cinvestav Irapuato, Km. 9.6 Libramiento Norte, P.O. Box 629, C.P. 36500, Irapuato, Guanajuato, México.

Accepted for publication 8 August 2006.

\begin{abstract}
Carrillo-Tripp, J., Lozoya-Gloria, E., and Rivera-Bustamante, R. F. 2007. Symptom remission and specific resistance of pepper plants after infection by Pepper golden mosaic virus. Phytopathology 97:51-59.

Pepper golden mosaic virus (PepGMV) is an important begomovirus infecting solanaceous crops in Mexico and Central America. Under controlled conditions for growth and inoculation with a low-pressure biolistic device, PepGMV-infected pepper plants consistently showed symptom remission or host recovery 12 to 15 days postinoculation (dpi). Inoculated plants initially developed the characteristic PepGMV symptoms; however, newer leaves presented a significant decrease or disappearance of

matic tissue. Nonetheless, viral DNA did not disappear during the evaluation period (up to $35 \mathrm{dpi}$ ), suggesting that a population of viral molecules escape from plant defensive mechanisms to maintain a subliminal, symptomless infection. Recovery was correlated with a specific resistance to PepGMV but not to Pepper huasteco yellow vein virus, a different geminivirus commonly found in mixed infections with PepGMV. Virus-related small interfering RNAs were detected in practically all tissues (from symptomatic to recovered leaves) but it was not possible to establish a correlation between concentration and symptom severity. The participation of a posttranscriptional gene silencing mechanism in the recovery process and specific resistance is discussed.
\end{abstract} symptoms. Younger asymptomatic, recovered leaves accumulated lower quantities of viral DNA and transcripts than the ones found in the sympto-

Geminiviruses are pathogens that infect a wide range of economically important crops. The family Geminiviridae is characterized by possessing a circular, single-stranded DNA (ssDNA) genome packaged into isometric twinned particles (13). Pepper golden mosaic virus (PepGMV) is a whitefly-transmitted, bipartite (genome divided in two components, Fig. 1A) member of the genus Begomovirus that naturally infects pepper, tomato, tobacco, and other solanaceous crops. PepGMV is widely distributed in Mexico and Central America and it has been reported in mixed infection with Pepper huasteco yellow vein virus (PHYVV) $(23,24,39)$, and more recently with Tomato yellow leaf curl virus (TYLCV) at the Yucatan peninsula (R. Díaz-Plaza and R. F. Rivera-Bustamante, unpublished data).

The typical symptoms induced by PepGMV (Tamaulipas strain) in pepper plants are yellow mosaic and wrinkle of the leaf and stunting of the plant. If a plant is infected at an early stage, only a couple of small, deformed fruits are obtained. Under experimental conditions, symptom remission had been randomly observed on PepGMV-infected plants in several laboratories $(2,8)$, but the recovery process has not been studied. Recovered plants show a disappearance or reduction of symptoms on the leaves that emerge after the initial two or three symptomatic leaves. Host recovery from viral infection has been reported in several plantvirus interaction systems $(4,31)$, including geminiviruses $(8,10)$, as well as in plants (obtained by transgenic resistance strategies)

Corresponding author: R. F. Rivera-Bustamante

E-mail address: rrivera@ira.cinvestav.mx

*The e-Xtra logo stands for "electronic extra" and indicates that the online version contains a photograph of an inoculation apparatus that is not included in the print edition.

DOI: 10.1094/PHYTO-97-0051

(c) 2007 The American Phytopathological Society
Additional keywords: host recovery, real-time polymerase chain reaction. that are inoculated with a viral replicon containing the transgene $(11,16,18,50,51)$. Most cases have been explained as RNAmediated or posttranscriptional gene silencing (PTGS) $(11,21$, $44,45,47)$. This is a common mechanism for eukaryotic organisms that is based on specific RNA degradation, is directed by doublestranded RNA (dsRNA), and produces 21- to 25-nt RNA fragments known as small interfering RNAs (siRNAs), considered a hallmark of the process $(4,38)$. It is currently accepted that PTGS protects plants from foreign genomes, such as viruses, or against transgenes (47). On the other hand, it has been proposed that viruses have co-evolved by developing strategies to suppress RNA silencing mechanisms $(34,44,49)$. Several viral proteins have been reported as suppressors of RNA silencing: helper component/proteinase (HC-Pro) protein from potyvirus $(1,7), 2 \mathrm{~b}$ protein from Cucumber mosaic virus (7), and p25 protein from Potato virus $X$ (48), among others (49). The number of reported viral suppressors, as well as the studies of their mechanism, is continuously increasing. It has been predicted that all viruses could have, although with different efficiencies, the ability to induce and somehow evade PTGS (34). For example, it was reported in one case that an active RNA silencing mechanism induced in response to the infection of tobacco by Tobacco streak virus (an RNA virus) was not sufficient to trigger host recovery (51), whereas in another case, the presence of an effective viral PTGS suppressor was unable to prevent the recovery (25). This implies that other factors may be also involved in the process.

Several reports have shown that geminiviruses (DNA viruses) can trigger and be targets of PTGS in a manner similar to plant RNA viruses. For example, transgenic plants expressing geminiviral genes could resist infection of homologous viruses by RNA silencing $(3,22,28)$; on the other hand, geminiviral silencing suppressors have also been reported $(5,12,42,46,49)$. In addition, geminivirus components have been used as vectors to silence the expression of host genes $(9,14,26,27,33,40)$. 
The association of PTGS with the recovery of a plant from a natural geminivirus infection was recently suggested since viral DNA accumulation and symptoms were inversely correlated to the presence of specific siRNAs (10). However, in another case there was no correlation, since virus-related siRNAs were detected in TYLCV-infected plants showing severe symptoms (22). It has been suggested that geminiviral dsRNA molecules could be generated by the aligning of convergent and complementary read-
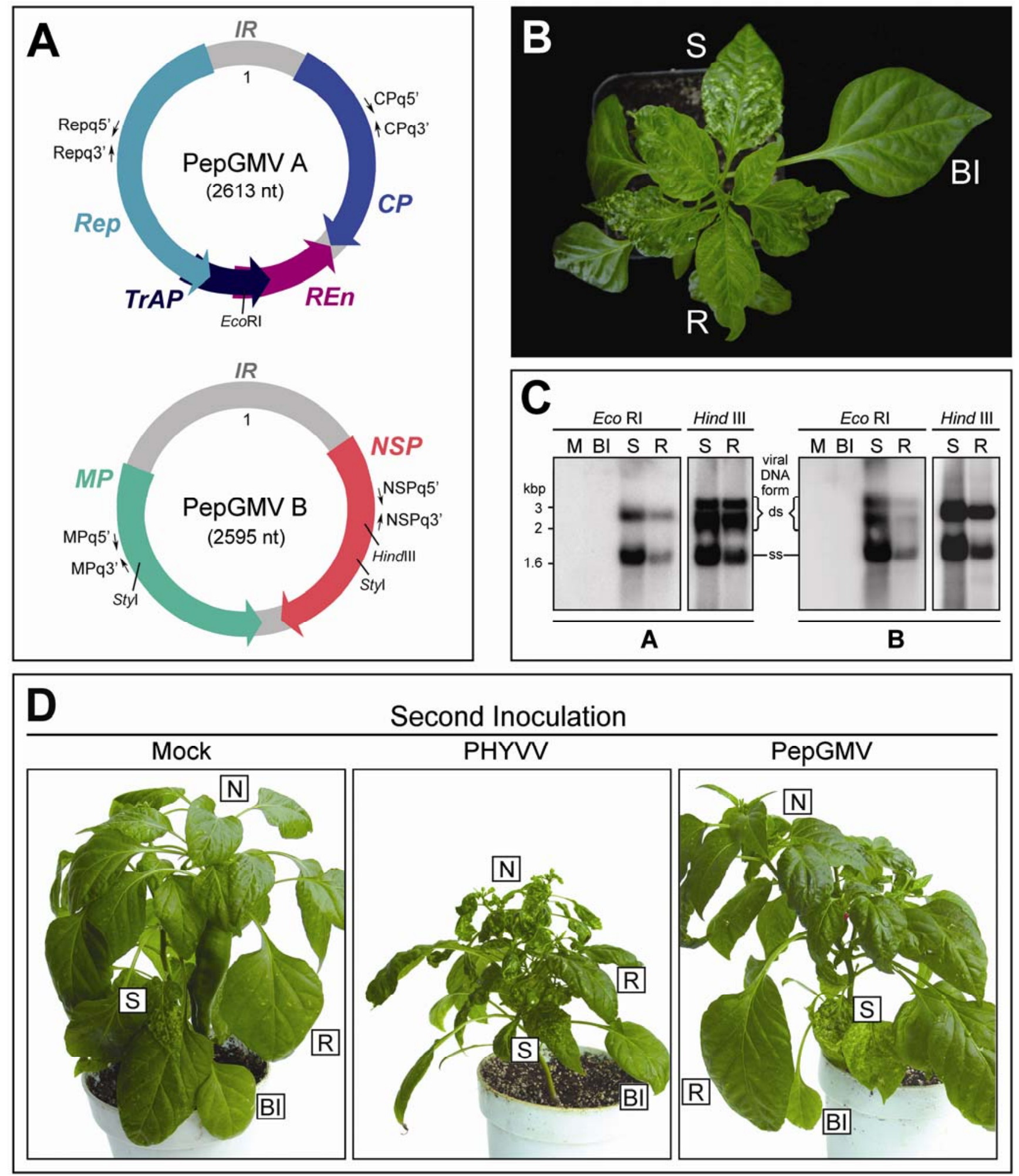

Fig. 1. Symptom remission and specific resistance of pepper plants infected with Pepper golden mosaic virus (PepGMV). A, Genomic map of PepGMV indicating: size of A and B components, open reading frames (Rep, replication associated-protein; TrAP, transcriptional activator protein; REn, replicationenhancement protein; CP, coat protein; MP, movement protein; and NSP, nuclear-shuttle protein), intergenic regions (IR), and PCR primers and restriction sites. B, PepGMV-infected and recovered pepper plant at 18 days postinoculation (dpi). C, Southern blot analysis of different tissues of a PepGMV-infected plant (BI, S, R) and a mock-inoculated plant (M) as control at 18 dpi. Viral forms (double stranded, ds; single stranded, ss) and size of linear DNA are indicated. D, PepGMVinfected and recovered plants were reinoculated at R1 leaves with pBluescript (Mock), Pepper huasteco yellow vein virus (PHYVV), or PepGMV. Pictures were taken 35 days after first inoculation (10 days after second inoculation). For B, C, and D: BI, below inoculation point; S, symptomatic; R, recovered tissue; N, new tissue (developed after second inoculation). 
through transcripts; by the presence of self-complementary hairpins in viral RNAs; or by a host RNA-dependent RNA polymerase (RdRP). In turn, those dsRNAs could trigger PTGS $(5,29,45)$

Our initial attempts to characterize a host recovery phenomenon observed in PepGMV-infected pepper plants were hampered by the low percentage of the inoculated plants that showed recovery after inoculation with the high-pressure, whole-plant biolistic procedure. The recent introduction of a new low-pressure, handheld inoculation device that allows a less severe, localized, oneleaf inoculation has facilitated the study of the remission process since under those conditions almost all inoculated plants developed a remission stage or recovery. In this paper we present a characterization of this recovery phenomenon, including comparative analyses (qualitative and quantitative) of viral nucleic acids in symptomatic and recovered tissues. Also, an initial study of the associated PTGS process was carried out as an attempt to elucidate its importance in the recovery and the specific resistance.

\section{MATERIALS AND METHODS}

Plant material. Pepper (Capsicum annuum L.) var. Sonora Anaheim was chosen for this study due to its high homogeneity in the development and severity of symptoms (24). Seeds were germinated in a bioclimatic chamber at 26 to $28^{\circ} \mathrm{C}$ with $16: 8 \mathrm{~h}$ (light/dark) photoperiod. Analysis of viral DNA and RNA was performed from different leaves (symptomatic, $\mathrm{S}$; recovered, R) harvested at distinct times. To identify the type of tissue and stage, the following nomenclature was used: A letter identified the tissue as $\mathrm{S}$ or $\mathrm{R}$; a superscript number on the left side indicated the collection day; a number on the right side represented the set of leaves collected. For example: ${ }^{18} \mathrm{R} 1$, first (1) set of Recovered leaves collected at $\underline{18}$ days postinoculation (dpi).

Viral clones. Dimeric clones of PepGMV (Tamaulipas isolate), previously referred to as Texas pepper virus (TPV) (39), were constructed following standard molecular procedures (35). Monomeric copies of both components of PepGMV (cloned in pBluescript) (Fig. 1A) were first released by digestion of the respective plasmid construct with the appropriate enzyme (EcoRI for PepGMV DNA A and HindIII for PepGMV DNA B) and then religated with a high viral-DNA/plasmid-vector ratio. Dimeric constructs (PepGMVAdimpBS and PepGMVBdimpBS) were selected by restriction enzyme analysis. Similar PHYVV dimeric clones (6) were used for mixed infections and specific resistance experiments.

Plant inoculation with viral DNA. Plants were inoculated by biolistic delivery with a modified handheld, low-pressure apparatus that allowed the targeting of a specific tissue (leaf). The third or fourth leaf on plants at the four-leaf stage (around 30 days postgermination) was directly shot at 100 to 120 psi helium pressure with tungsten particles $(0.7 \mathrm{~mm}$, BioRad, Hercules, CA) covered with viral DNA (15) (PepGMVAdimpBS + PepGMVBdimpBS) or with pBluescript for mock-inoculations ( $5 \mu \mathrm{g}$ of each dimeric construction for five plants). For resistance experiments, the youngest expanded leaves of recovered and mock plants were reinoculated using the same biolistic procedure 24 days after the first inoculation.

Total DNA extraction. Total DNA from infected and mockinoculated plants was extracted as described (24) and used for Southern blot analysis, viral infectivity assays, and viral quantification experiments.

Southern blot analysis. Five micrograms of total digested DNA per well was loaded in a $1 \%$ agarose gel. After electrophoresis, DNA was transferred to Hybond $\mathrm{N}^{+}$membrane (Amersham Biosciences, Piscataway, NJ) by capillary action with a $20 \times$ solution of $0.15 \mathrm{M} \mathrm{NaCl}$ plus $0.015 \mathrm{M}$ sodium citrate (SSC), and UV-crosslinked. The complete PepGMV DNA A was used as probe. In the case of PepGMV DNA B, the smallest fragment (873 bp) obtained after digestion with StyI was used (Fig. 1A). Probes were radioactively labeled using Redi prime II kit and $\left(\alpha-{ }^{32} \mathrm{P}\right)$ dCTP (Amersham). Hybridizations were performed overnight at $50^{\circ} \mathrm{C}$ as described in Hutvágner et al. (20). Membranes were then washed twice in $2 \times \mathrm{SSC}, 1 \%$ sodium dodecyl sulfate (SDS), and twice in $0.2 \times \mathrm{SSC}, 1 \%$ (SDS), all at $50^{\circ} \mathrm{C}$. Hybridization signals were detected on a phosphorimager system.

Viral infectivity assay. Total DNA $(20 \mu \mathrm{g})$ from $\mathrm{S}$ and $\mathrm{R}$ tissues was fractionated in $1 \%$ agarose gels. DNA fragments in the size range of 1 to $3 \mathrm{~kb}$ were purified using a QIAquick gel extraction kit (QIAGEN Inc., Valencia, CA). For the infectivity assays, $8 \mu \mathrm{g}$ of the recovered, size-selected DNA was used to prepare enough microparticles to inoculate five plants by the biolistic procedure described above.

Total RNA extraction. Total RNA from recovered, symptomatic, and mock tissue samples was extracted with the TriZOL reagent (Life Technologies, Carlsbad, CA) followed by Turbo DNase I treatment (Ambion) and phenol/chloroform (1:1) extraction. RNA extracts were then used in reverse-transcription polymerase chain reaction (RT-PCR) and small interfering RNAs (siRNA) analyses.

Real-time PCR. For real-time PCR, five plants from each time point $(18,24$, and $28 \mathrm{dpi})$ were dissected to obtain each sample (BI, S and Rn samples). DNA and RNA were extracted from each sample. For relative quantification of viral DNA, total plant DNA was treated with RNase A (USB Corp., Cleveland, OH). For relative quantification of viral RNA, $1 \mu \mathrm{g}$ of total RNA was treated with amplification-grade DNase I (Life Technologies) for $1 \mathrm{~h}$ at $37^{\circ} \mathrm{C}$; after heat inactivation, $200 \mathrm{ng}$ was used to generate cDNA with Superscript II reverse transcriptase (Life Technologies) using specific primers.

Real-time PCR was performed in a BioRad iCycler thermocycler using Platinum SYBR Green qPCR SuperMix UDG (Life Technologies), with a final concentration of fluorescein $=10$ $\mathrm{nM}$ according to supplier's recommendations. For 20- $\mu$ l reactions, $2 \mu \mathrm{l}$ of DNA (1.6 $\mathrm{ng}$ ) or cDNA (1:10 of reverse transcription reaction) was used along with $1 \mu \mathrm{l}$ of each $4 \mu \mathrm{M}$ primer and $10 \mu \mathrm{l}$ of $2 \times$ supermix. A melting curve was programmed after each run to verify the lack of primer dimerization or nonspecific amplification. Maximal amplification efficiency was assumed for all samples at a determined threshold in log phase with the following formula: $\mathrm{T}=X 2^{\mathrm{CT}}$, where $T$ was the selected threshold of fluorescence units, $X$ was the initial copy number, and CT was the cycle number crossing the threshold. Relative units were calculated against the sample with the highest concentration. The primers used in this study are as follows: for Rep gene (encoding replication-associated protein), PepGMVRepq5' (5'-CAAAGCTGGTGATCCGAAAACG-3') and PepGMVRepq3' (5'-GTTAAACGAGGATAATGGATAAGG-3'), expected PCR product of $121 \mathrm{bp}$; for $C P$ gene (encoding coat protein), PepGMVCPq5' (5'CCCATCGTGTAGGCAAGCGTTTCTG-3') and PepGMVCPq3' (5'-CATGACGCTGTTGGTGTGGTTCTTG-3'), expected PCR product of $104 \mathrm{bp}$; for $M P$ gene (encoding movement protein), PepGMVMPq5' (5'-GGATAACGAGTCATTACAAGC-3') and PepGMVMPq3' (5'-GGTCCTTCAGTGAAAAGAATG-3'), expected PCR product of $94 \mathrm{bp}$; for $N S P$ (encoding nuclear shuttle protein), PepGMVNSPq5' (5'-GCATACATGAAAACCAATATG$\left.3^{\prime}\right)$ and PepGMVNSPq3' (5'-GCTTAATATACGACCTGCTTC$3^{\prime}$ ), expected PCR product of 122 bp (Fig. 1A). The primers for internal normalization were designed for $18 \mathrm{~S}$ pepper sequence: 18Sq5' (5'-CGGGATCGGAGTAATGATTAACAG-3') and 18Sq3' (5'-GGCAAATGCTTTCGCAGTTGTTCG-3') and produced a 108-bp PCR fragment.

Viral siRNA analysis. For siRNA analysis, 40 to $60 \mu \mathrm{g}$ of total RNA was heat denatured and separated by $15 \%$ denaturing polyacrylamide gel electrophoresis (PAGE) in Tris-borate-EDTA 

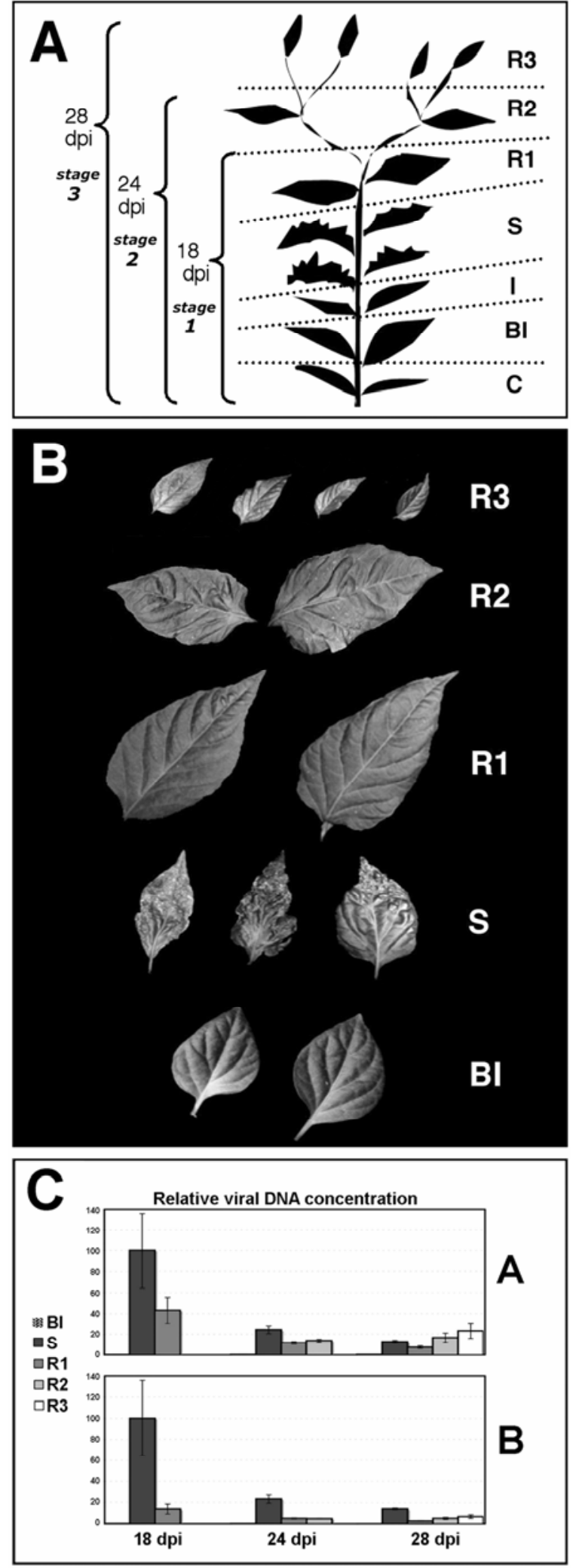

Fig. 2. Analysis of viral DNA in plants recovered from Pepper golden mosaic virus (PepGMV) infection at different stages after inoculation. A, Stages scheme showing the different leaves' conditions and times when they were present. C, cotyledons; BI, below inoculated; I, inoculated; S, symptomatic tissue; Rn, different levels of R tissues; dpi, days postinoculation. B, Leaves from a PepGMV-infected and recovered plant at 28 dpi. C, Relative viral DNA concentration of each PepGMV component (A and B) measured by real-time polymerase chain reaction at indicated tissues and stages. Each bar corresponds to the mean value from five plants; maximum value of each component was taken as 100 . Error bars refer to standard error of the mean.
(TBE) $0.5 \times$ buffer at $800 \mathrm{~V}, 20 \mathrm{~mA}, 10 \mathrm{~W}$ in a $18-\mathrm{cm}$-long apparatus for approximately $2 \mathrm{~h}$. RNA was electro-transferred to Hybond- $\mathrm{N}^{+}$membranes (Amersham Biosciences) using a similar buffer at 300 to $400 \mathrm{~mA}, 10$ volts, for $1 \mathrm{~h}$. After transferring and before hybridization, the membranes were UV-crosslinked. A 25-nt-long DNA oligonucleotide was used as molecular size marker (35). Membranes were probed with different regions of the PepGMV genome: total component A (2.6 kb) or B $(2.6 \mathrm{~kb})$; CP (a 104-bp fragment obtained by PCR with primers PepGMVCPq5' and PepGMVCPq3'); Rep (121-bp fragment obtained by PCR with primers PepGMVRepq5' and PepGMVRepq3'); and IR (287-bp fragment obtained by PCR with primers JM23 and JM24 as described in Méndez-Lozano et al. [24]). Probes were labeled using Redi prime II kit and $\left(\alpha-{ }^{32} \mathrm{P}\right)$ dCTP (Amersham). Hybridization was carried out overnight according to Hutvágner et al. (20). Membranes were washed twice for $20 \mathrm{~min}$ in $2 \times \mathrm{SSC}, 1 \% \mathrm{SDS}$ and once for $10 \mathrm{~min}$ in $0.2 \times \mathrm{SSC}, 1 \% \mathrm{SDS}$; all washes were at $50^{\circ} \mathrm{C}$. A phosphorimager system was used to detect hybridization signals.

\section{RESULTS}

Characterization of the symptom remission or recovery process. An effort to improve the previously described biolistic inoculation procedure (15) resulted in a new handheld device that allows localized inoculation of a single leaf. This low-pressure $(<200$ psi) inoculation was less detrimental than the previous procedure while still maintaining a high efficiency (95 to $100 \%$ infection rate) when using PepGMV-DNA dimeric constructs. In addition, a high percentage of the plants inoculated with PepGMV using the handheld device consistently showed a recovery or symptom remission. Therefore, several experiments were carried out to characterize the recovery process observed.

Plants were inoculated by delivering cloned PepGMV DNA (Fig. 1A) directly onto the third or fourth leaf. The following two to three newly emerging leaves of the inoculated plants developed typical yellow mosaic and wrinkle symptoms 12 to $15 \mathrm{dpi}$ (symptomatic or $\mathrm{S}$ tissue). The subsequent leaves consistently showed a reduction in severity of the symptoms, and in most cases, they were practically asymptomatic (recovered or R tissue; Figs. 1B and 2A, B).

In previous reports of plants recovering after a viral infection, it was shown that viral genome concentration was usually diminished or depleted in $\mathrm{R}$ tissues $(10,11,18,31,32,47,51)$. To verify the quality and quantity of PepGMV DNA in $S$ and R tissues, a comparative analysis was carried out. Southern blot analysis showed similar geminiviral DNA forms in both tissues (Fig. 1C). Overexposure of radiography films did not show any evidence of defective viral DNA molecules in either case (data not shown). However, in terms of quantity, the concentration of both viral DNAs (A and B) observed in R tissue was significantly lower than the one detected in $\mathrm{S}$ tissue. The difference noticed in the Southern blot analysis (Fig. 1C, compare lanes S and R) was also corroborated by real-time PCR (Fig. 2C).

To confirm the infectivity of the viral DNAs present in both tissues, total DNA was extracted from $\mathrm{S}$ and $\mathrm{R}$ leaves and used to inoculate additional pepper plants. Both DNA preparations ( $\mathrm{S}$ and R) were highly infectious (70 to $100 \%$ ) and induced symptoms identical to those induced by cloned viral DNAs. In addition, plants infected with both DNAs showed similar recovery. Therefore, the viral population found in the recovered (R) tissue maintained its ability to replicate and to induce symptoms and subsequent recovery.

Recovered plants showed specific viral resistance. Recovered leaves from PepGMV-infected plants were reinoculated 24 days after the first inoculation with the same geminivirus (PepGMV), with a second geminivirus (PHYVV), or with plasmid DNA (mock inoculation). Plants were then incubated under either 
greenhouse or growth chamber conditions and the newly emerged leaves carefully evaluated for symptom development. Recovered plants that were reinoculated with either plasmid vector alone or with PepGMV DNA did not exhibit any symptoms in the newly emerging tissue after the second inoculation (Fig. 1D, "N" in mock and PepGMV). These plants showed normal growth and leaves reached normal size. In contrast, plants reinoculated with PHYVV DNA developed the typical and strong synergistic symptoms induced by the PHYVV-PepGMV mixture: severe wrinkling and yellowing of the leaves and severe stunting of the plant (Fig. 1D, "N" in PHYVV). This suggested that the R tissues displayed a specific resistance to reinfection by PepGMV since they maintained the competence to become infected by PHYVV. On the other hand, plants that were first mock-inoculated (pBluescript DNA) and later reinoculated with PepGMV did develop typical symptoms, confirming that the resistance observed was not a problem with inoculation due to the age of the plant or its developmental stage (data not shown). Interestingly, in all plants inoculated with both viruses, either simultaneously or sequentially (PepGMV plus PHYVV), the strong reaction did not recede and no remission was ever observed. The plants remained stunted, curly, and nonproductive. Similar results were obtained with plants first inoculated with PHYVV (and reinoculated with PHYVV, PepGMV, and pBluescript, data not shown), demonstrating that the resistance observed was not exclusive to pepperPepGMV interaction.

Analysis of viral DNA in recovered plants. To verify if the decrease in viral DNA concentration was either a temporary or a permanent effect, the analysis of viral DNA in the recovered plants was extended for a longer period. To facilitate such analysis, the recovered tissue collected was divided into three growth stages as shown in Figure 2A. Stage 1, up to 18 dpi (3 to 5 days after symptom appearance) included the following tissues: cotyledons and leaves below the inoculation site $\left({ }^{18} \mathrm{BI}\right)$, the inoculated leaf $\left({ }^{18} \mathrm{I}\right)$, the symptomatic leaves $\left({ }^{18} \mathrm{~S}\right)$, and the first set of leaves that showed recovery $\left({ }^{18} \mathrm{R} 1\right)$. Stage 2 , up to $24 \mathrm{dpi}$, included ${ }^{24} \mathrm{BI}$, ${ }^{24} \mathrm{I},{ }^{24} \mathrm{~S},{ }^{24} \mathrm{R} 1$, and an additional set of recovered leaves $\left({ }^{24} \mathrm{R} 2\right)$. Finally, stage 3 , up to $28 \mathrm{dpi}$, included ${ }^{28} \mathrm{BI},{ }^{28} \mathrm{I}$, and ${ }^{28} \mathrm{~S}$, and an additional three or more sets of recovered leaves $\left({ }^{28} \mathrm{R} 1,{ }^{28} \mathrm{R} 2\right.$, and ${ }^{28} \mathrm{R} 3$ ). At this stage, a second branching was already present. Figure 2B shows the typical characteristics of the leaves from a single plant at stage 3 .

Viral DNA was quantified by real-time PCR using the primers indicated in Figure 1A. Each viral component was analyzed with two sets of primers, which produced similar results. To compare the amount of viral DNA in each tissue, all values were normalized using the results of a similar analysis for a host gene. To avoid interference with the DNA introduced as inoculum, the inoculated leaf was not included in the analysis. Figure $2 \mathrm{C}$ shows the comparison of the viral DNA values in different tissues at the three stages. At stage 1, three types of tissues were analyzed: ${ }^{18} \mathrm{BI}$, ${ }^{18} \mathrm{~S}$, and ${ }^{18} \mathrm{R} 1$ leaves. Whereas viral DNA was barely detectable in ${ }^{18} \mathrm{BI}$ leaves, ${ }^{18} \mathrm{~S}$ tissue presented a high concentration of both viral components. The amount of viral DNA in these samples was the highest of all tissues and stages analyzed. On the other hand, viral DNA concentration in the first set of recovered tissue, ${ }^{18} \mathrm{R} 1$, was dramatically lower than the one observed for ${ }^{18} \mathrm{~S}$ leaves. The differences in viral DNA concentration between ${ }^{18} \mathrm{~S}$ and ${ }^{18} \mathrm{R} 1$ ranged from $60 \%$ for component A to $80 \%$ for component B. At stage 2, the relationship of DNA values was similar to those found in stage 1 , with no viral DNA detected in ${ }^{24} \mathrm{BI}$ leaves, a high concentration in the ${ }^{24} \mathrm{~S}$ tissue, and a significantly lower DNA concentration in the recovered tissues ${ }^{24} \mathrm{R} 1$ and ${ }^{24} \mathrm{R} 2$. However, although in both stages $\mathrm{S}$ tissue contained the highest amount of viral DNA, a significant reduction was observed when ${ }^{24} \mathrm{~S}$ tissue was compared with ${ }^{18} \mathrm{~S}$. Whether the virus initially present in ${ }^{18} \mathrm{~S}$ was degraded or exported to other tissues not tested here is not known. In contrast, both recovered leaves, ${ }^{24} \mathrm{R} 1$ and
${ }^{24} \mathrm{R} 2$, showed similar concentration for both components, suggesting that a steady state had been reached. At stage 3, again almost no viral DNA was detected in ${ }^{28} \mathrm{BI}$ whereas the concentration of viral DNA in ${ }^{28} \mathrm{~S}$, although still the highest in the stage, was even lower than the one obtained in the previous stage (compare ${ }^{28} \mathrm{~S}$ versus ${ }^{24} \mathrm{~S}$ ), showing a continuous reduction over time in the symptomatic tissue. In the recovered tissue, the concentration of viral DNA (both components) maintained a similar steady-state level, as observed in the first two samples $\left({ }^{28} \mathrm{R} 1\right.$ and $\left.{ }^{28} \mathrm{R} 2\right)$. However, DNA concentration was slightly higher (especially noticeable for component A) in the youngest apical leaves $\left({ }^{28} \mathrm{R} 3\right)$. These data, along with the fact that viral DNA in $\mathrm{R}$ leaves is infectious, suggest that a small viral population is able to escape the defense response displayed by the plant maintaining a subliminal infection, which could be important for disease dissemination in crop plants.

Viral RNA concentration in recovered plants. Although total viral DNA analysis is important data for viral infection studies, it can be a misleading or incomplete parameter in terms of viral activity. Therefore, the concentration of viral RNA as an indicator of viral transcriptional activity was also determined. Real-time RT-PCR analyses for Rep, $C P$, and $M P$ genes were performed using RNA extracted from the same leaf samples used previously to quantify viral DNA. All values were expressed in terms of percentage of the maximum value obtained for each gene.

Therefore, although the diagrams (Fig. 3) allow the comparison of the levels of a specific RNA (e.g., $C P$ RNA) in different leaves at different times, this format does not allow the comparison of the RNA levels between different genes (e.g., to compare promoter strengths). As expected, all viral RNAs assayed were barely detectable in all collected BI leaves at all stages, suggesting that no viral RNA accumulated and that probably no viral transcriptional activity was carried out in those tissues. Figure $3 \mathrm{~A}$ shows the relative concentration of RNA from the selected viral genes (Rep, $C P$, and $M P$ ) in different tissues at the three stages analyzed. In general, for stage 1, viral RNAs showed a similar pattern to the one observed for viral DNA: a high concentration in the ${ }^{18} \mathrm{~S}$ tissue and a low concentration in ${ }^{18} \mathrm{R} 1$-tissue. At stage 2 , the initial response was also similar for all assayed genes, i.e., high concentration in $\mathrm{S}$ tissue and a significant reduction in $\mathrm{R} 1$ leaves. However, contrary to the pattern observed for viral DNA, the concentration in R2 leaves of all viral RNAs was significantly elevated and in the case of $C P$, the concentrations were as high as those obtained in symptomatic tissues. It is important to note that at this stage, R2 leaves represent the youngest tissue in the plant. This suggested that either viral transcriptional activity increased in ${ }^{24} \mathrm{R} 2$ leaves or the degradation of viral RNA is somehow less efficient in those tissues, or both. Finally, at stage 3, the general pattern of the viral RNA levels again showed similarities with its respective DNA patterns: a peak in the $\mathrm{S}$ tissue with a lower plateau for R1 and R2 tissues. However, two of the genes tested (Rep and $C P$ ) showed high RNA concentration in the youngest R3 tissues (resembling the one observed in ${ }^{24} \mathrm{R} 2$ ). This peak correlates with the higher concentration of component A observed in Figure $2 \mathrm{C}$.

To facilitate the analysis of the fate of viral RNA in S and R1 leaves over time, the corresponding data are presented independently in Figures 3B and 3C. Figure 3B shows that RNA levels of Rep and $C P$ in the $\mathrm{S}$ tissue decreased continuously over time similar to the reduction of viral DNA in the same tissue. The decrease in RNA levels, however, was not as drastic as that observed for DNA (Figs. 2C and 3B). MP RNA levels on the other hand, showed an increase from the initial concentration at 18 dpi to a peak at $24 \mathrm{dpi}$, and again decreased to a lower concentration detected at $28 \mathrm{dpi}$, contrasting with viral DNA B behavior (compare viral DNA B in ${ }^{18-28} \mathrm{~S}$ from Fig. $2 \mathrm{C}$ with $\mathrm{MP}$ in Fig. 3B). These data indicate that $S$ tissue is transcriptionally active at most of the times tested. Interestingly, the relative concentrations of viral 
RNA in R1 tissue showed a completely different pattern (Fig. 3C), suggesting that $\mathrm{S}$ and $\mathrm{R} 1$ tissues have important physiological differences. In R1 tissue, all viral transcripts decreased dramatically at $24 \mathrm{dpi}$ and remained in a low steady state at $28 \mathrm{dpi}$, similar to the behavior of DNA in R1 tissue. Clearly, the low levels of viral transcripts in R1 tissue correlate

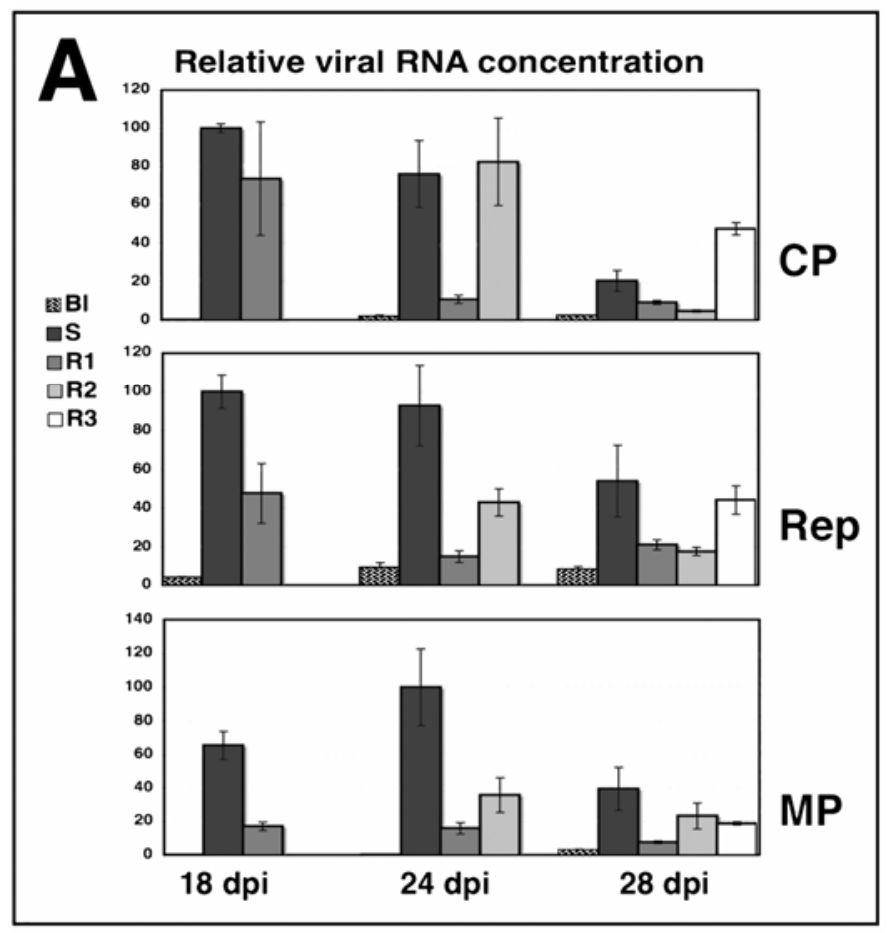

B

Relative viral RNA concentration in S

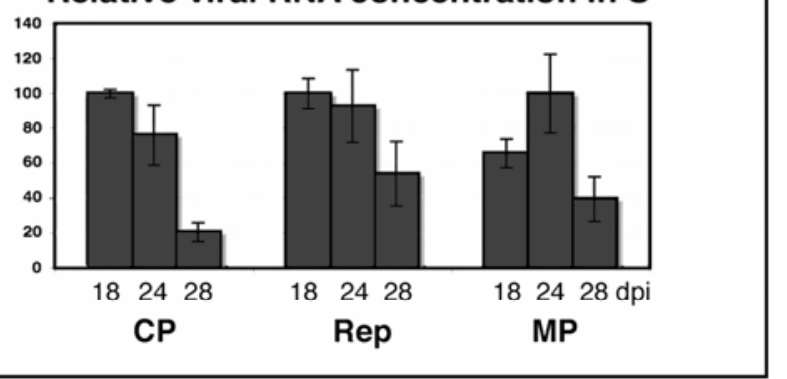

C
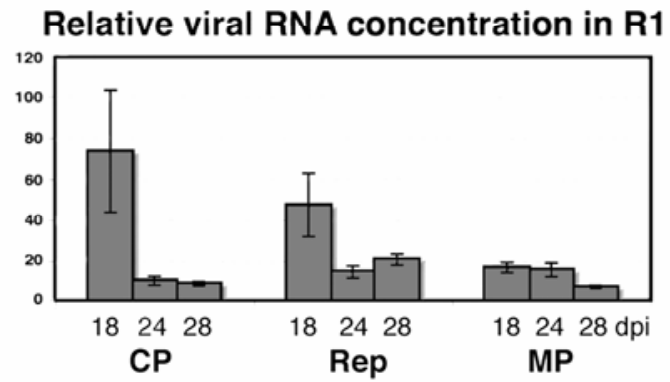

Fig. 3. Relative quantification of viral transcripts by real-time polymerase chain reaction. A, Concentration in several tissues at different stages: $\mathrm{CP}$, transcript of coat protein; Rep, transcript of replication-associated protein; and $\mathrm{MP}$, transcript of movement protein (BI, below inoculated; S, symptomatic tissue; Rn, different levels of $\mathrm{R}$ tissues). B, Concentration of the transcripts in symptomatic tissue, and $\mathbf{C}$, Concentration of the transcripts in $\mathrm{R} 1$ tissue at different stages. Each bar corresponds to the mean value from five plants; maximum value of each transcript was taken as 100. Error bars refer to standard error of the mean. with low viral DNA levels, as both viral nucleic acids were in lesser amounts in R1 tissue than in S tissue. It does appear that the mechanism responsible for the low levels in R1 tissue (i.e., specific degradation, exportation, or lower synthesis) was turned on before $18 \mathrm{dpi}$.

Detection of siRNAs during several stages of infection and recovery. A functional PTGS system is generally associated with the presence of siRNA molecules. Therefore, to verify if this mechanism was involved in the decrease of viral transcripts in recovered plants, as well as in the detected specific resistance, the presence of PepGMV-related siRNAs was studied in tissues collected along a similar time period.

In the system reported here, two major siRNA species were distinguishable in almost all samples (Fig. 4) in the size range previously reported by Hamilton et al. (17), i.e., 21 to $22 \mathrm{nt}$ for the small RNA species and 24 to $25 \mathrm{nt}$ for the large population. As shown in Figure 4, PepGMV DNA A-related siRNAs were detected only in tissues where viral DNA and RNA were previously found. Using a ${ }^{32} \mathrm{P}$-labeled probe that included the entire component A, siRNAs were detected as early as 10 dpi when only symptomatic tissue was present in the infected plant. This suggested that the defense response that generates siRNAs was probably turned on in the symptomatic tissue when viral expression is high. Samples collected after the first leaf showing recovery had expanded (enough to assure the lack of symptoms; $15 \mathrm{dpi}$ ), showed the presence of PepGMV-related siRNA in both symptomatic (S) and recovered (R1) tissues. Similarly, siRNAs were detected in samples collected at 20 or 35 dpi when several stages of recovered tissues were present (R1 and R2 at 20 dpi or R1, R2, and R3 at $35 \mathrm{dpi}$ ). As expected, siRNAs were not detected either in BI leaves (correlating with the absence of viral DNA and RNA in those leaves) or in mock-inoculated plants (Fig. 4).

Hybridization with probes specific for PepGMV DNA B produced similar results to those shown for PepGMV DNA A (Fig. 5). On the other hand, additional probes from different regions of PepGMV DNA A revealed that siRNAs were generated from transcripts originating from the entire genome, including the intergenic region (Fig. 5). In contrast to the results reported for African cassava mosaic virus (ACMV-[CM]) (10), there was not a clear inverse correlation between the concentration of viral RNA detected (and symptoms) and the concentration of virus-related siRNAs. In this case, the concentration of viral-related siRNAs (based on the intensity of the hybridization signal), was similar, or in some cases even higher, in the tissue showing strong symptoms (S) and having the highest concentration of viral DNA and RNA. Another important observation was the strong hybridization signal (as an indication of a high concentration of siRNAs) obtained with probes derived from the intergenic region. This suggests an important level of transcription through this regulatory element (Fig. 5).

\section{DISCUSSION}

The introduction of a handheld inoculation device was essential to the development of this work since it allowed a localized inoculation (important for the reinoculation experiments), facilitated the inoculation of a wider variety of plant sizes and developmental stages, and provided greater control over the amount of inoculating DNA because the entire preparation is inoculated on a specific spot.

The recovery of a plant from a virus infection is a phenomenon that has been observed for many years in several systems (4), but only recently has information about the molecular basis for such phenomenon started to emerge. At this point, the variations observed in similar plant-virus systems make it difficult to extrapolate results from one system to another. Therefore, it was of great interest to characterize the recovery phenomenon observed in the interaction between pepper and PepGMV since this host-virus 
combination is the predominant one in Mexican and Central American horticultural fields.

The comparison of the concentration of geminiviral DNA in different tissues or plants is not a simple task. The number of infected cells is very low and probably variable from tissue to tissue, depending on factors such as developmental stage or time of inoculation. Additionally, the sites for virus replication and accumulation are not necessarily the same. Therefore, two tissues with a similar concentration of total viral DNA might have a completely different significance for the virus cycle. In an attempt to reduce the impact of those variables, DNA determination was done using two different methodologies, and the analyzed samples included the entire, formed leaves (symptomatic or asymptomatic), assuming that the number of cells per leaf remained essentially the same. In the case of real-time PCR, this was carried out using several primer sets for the virus genome and a primer set for a host gene. All viral values were then normalized to host gene values. In theory, the number of copies of viral genome per host genome could be calculated. However, since the number of infected cells is unknown (but expected to be low), the results could only be interpreted as the amount of viral DNA per leaf (without differentiating whether there was a low number of cells with a high number of viral copies or a large number of cells with a low number of copies of virus genomes). Preliminary results with in situ hybridization experiments with PepGMVinfected pepper plants (I. Rentería-Canett and R. F. RiveraBustamante, unpublished data), as well as published data with other viruses (19) suggest that the first possibility is more likely.

Analysis of viral DNA present in S and R tissues revealed that its quality was similar in terms of infectivity and viral forms detected. However, a major difference in the quantity was detected since $\mathrm{S}$ tissue contained a higher concentration of viral DNA than did R tissue. This observation was confirmed by both Southern blot and real-time PCR analyses. Real-time PCR was very useful for quantifying the difference in total viral DNA concentration. On the other hand, Southern blot assays were an important complement as they showed that $\mathrm{S}$ and $\mathrm{R}$ tissues presented similar patterns of the main viral forms (ss and ds). However, minor viral intermediates (e.g., from a recombination-dependent replication, RDR) as reported by Preiss and Jeske (30) would not be detected with the methods used here. It will be very interesting to compare the patterns of such RDR intermediates in S and R tissues.

In early works with ACMV and Nicotiana benthamiana, it was shown that the presence of defective molecules (smaller-thanunit-length molecules) was associated with a decrease in symptoms and replication $(36,37)$. Therefore, a possibility for the reduction of viral DNA in R tissue was the formation of such defective forms. In PepGMV-recovered plants, no abnormal forms were detected in several hybridization experiments even after linearization of the viral genome. In addition, the PCR analyses designed from different regions of the genome gave similar results, showing that few, if any, defective, smaller-than-unit-length molecules were present in the infected plant.

Recovered plants remained asymptomatic and developed normally under controlled conditions. In these plants, the relative concentration of viral DNA in $\mathrm{S}$ tissue decreased over time $\left({ }^{18} \mathrm{~S}\right.$ to ${ }^{28} \mathrm{~S}$ ). The migration of virus particles/complexes to other tissues, and some DNA degradation, possibly contributed to reduce the initial relative concentration in S. For example, the main replication site for the virus is usually associated with the apical tissue. As the plant grows, such replication sites would follow the development of the plant, concentrating in tissues near the apex, thereby reducing the replication rate in $\mathrm{S}$ tissue. This pattern is clearly observed at $28 \mathrm{dpi}$, when several levels of recovered leaves are present. R3 tissue showed a slight increase of the relative concentration of viral DNA and RNA when compared with the older $\mathrm{R} 1$ and R2 tissues. In any case, the concentration of viral DNA in

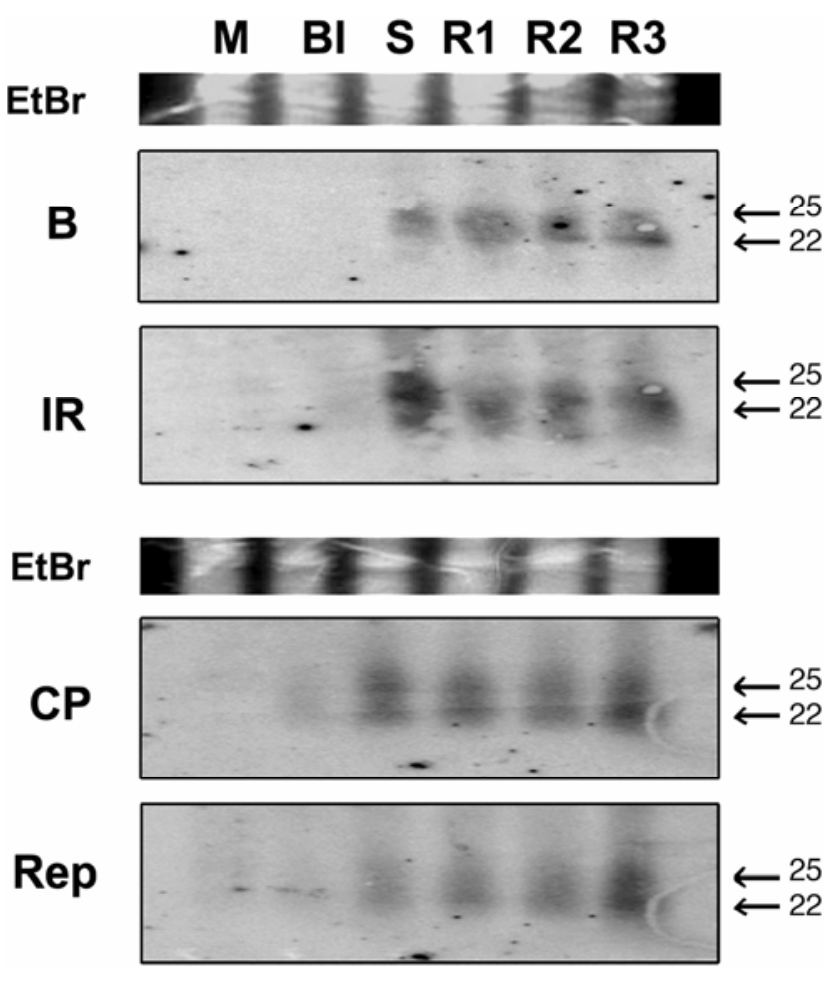

Fig. 5. Northern blot analysis of small interfering RNAs (siRNAs) extracted from Pepper golden mosaic virus (PepGMV)-infected plants showing recovery (BI, below inoculation point; $\mathrm{S}$, symptomatic; $\mathrm{Rn}$, recovered tissues) or (M) mock-inoculated plants. Samples were collected at 35 days postinoculation (dpi) and hybridized with different regions of PepGMV DNA A (coat protein $[\mathrm{CP}]$, replication-associated protein [Rep], and intergenic region (IR) [Fig. 1A]) or with the entire PepGMV DNA B (B) as probes. Arrows show the approximate size of two siRNAs species. Ethidium bromide (EtBr) staining gels were used as the loading control.
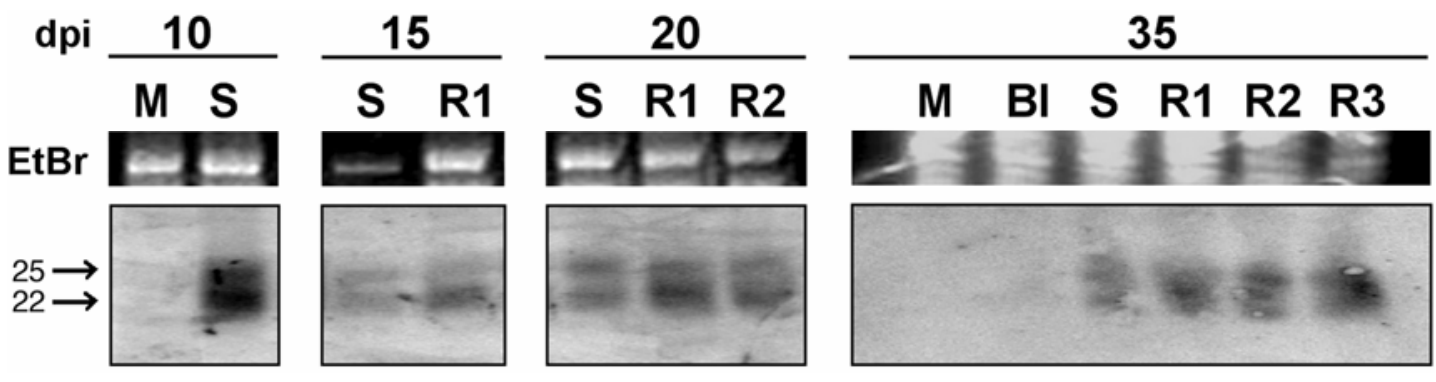

Fig. 4. Northern blot analysis of small interfering RNAs (siRNAs) from different tissues of Pepper golden mosaic virus (PepGMV)-infected and recovered plants (BI, below inoculation point; S, symptomatic; Rn, recovered tissues) or mock-inoculated plants (M). Samples were collected at different times and hybridized with the entire PepGMV DNA A as probe. Arrows show the approximate size of two siRNAs species. Ethidium bromide (EtBr) staining gels were used as the loading control. 
the apical $\mathrm{R}$ leaves never reached the levels detected in ${ }^{18} \mathrm{~S}$ tissue, suggesting that a concentration threshold has to be attained to generate or induce symptoms.

Real-time PCR analysis showed a good correlation between the relative concentration of viral RNA and DNA. The three transcripts monitored $(C P, R e p$, and $M P)$ decreased considerably in recovered tissue $(\mathrm{R} 1)$ at the first stage $(18 \mathrm{dpi})$ and showed slight increments in the youngest recovered tissue of the later stages $\left({ }^{24} \mathrm{R} 2\right.$ and $\left.{ }^{28} \mathrm{R} 3\right)$. A circular, typical cause-effect uncertainty can be mentioned when trying to explain the low levels of viral nucleic acids at a specific time in a specific tissue. However, a general view could be expressed as follows. Plant defenses (e.g., RNA silencing and possibly others) initially triggered in the symptomatic tissue (S) due to the high levels of viral RNA are responsible for reducing viral RNA in the emerging R1 leaves. Low concentration of viral RNAs results in a lower level of viral replication, which results in a viral concentration below a threshold required for symptoms. Low DNA titer, in addition to the still-acting PTGS, results in low expression of viral transcripts.

Although recovery has been reported for other geminiviruses (10), the specific resistance of the recovered tissue against the same virus was not reported. In the system reported here, the recovered tissue failed to be reinfected by the same geminivirus whereas it was readily infected with the second virus (PepGMV or PHYVV, respectively), suggesting the induction of a specific resistance stage. This type of resistance has been typically associated with PTGS. A generally accepted idea is that the specificity of the resistance is based on the formation of dsRNA, which in turn, triggers the degradation of related RNAs. Therefore, a nonrelated virus would not be recognized by the specific siRNAs generated in response to the first infection (41). A general sequence comparison between PHYVV A and PepGMV DNA A showed that these viruses maintain only $65.5 \%$ identity. However, in some segments (e.g., CP and NSP genes) sequence identity is as high as $83 \%$. If the resistance observed was merely based on random sequence identity, it could be expected that some PHYVV RNAs originating in the highly conserved regions could be also degraded and therefore affect the synergism. However, it seems that this might not be the case. Preliminary results suggest the presence of "hot spots" in the viral genome for the generation of siRNAs (data not shown).

The presence of PepGMV-related siRNAs suggests, indeed, that a PTGS mechanism is involved in the recovery of the inoculated plants. Even so, there was no clear inverse correlation between the concentrations of siRNAs and viral transcripts (and symptom strength) in the tissues and times tested. It is likely that in addition to PTGS, processes such as transcriptional gene silencing (TGS) based on DNA methylation (5), and other defensive mechanisms could be acting in parallel. Experiments currently in progress to characterize the levels of methylation of viral DNA in $\mathrm{S}$ versus $\mathrm{R}$ tissue as well as the siRNA population (E. A. Rodríguez-Negrete and R. F. Rivera-Bustamante, unpublished data) support this hypothesis.

It has been shown that TrAP (AC2, C2) protein of geminiviruses has the properties of a silencing suppressor $(5,42,43,49)$. It is possible that the differences observed in the silencing efficiency of several systems might be explained by the variability in both TrAP sequences and host factors that interact with it.

In the case of the synergism in pepper, it is possible that silencing suppressors that independently are inefficient (and therefore induce recovery), can act in combination to shut down plant defenses. Additionally, it is possible that TrAP might not be the only factor involved in this recovery-synergism process. Any complementation between co-infecting viruses that facilitates or enhances any process of the second virus (replication, movement, gene expression) might result in an increased, although temporal, fitness that might augment viral titers, as observed in synergism.
It was interesting that in this PepGMV-pepper system, in contrast to cassava-infecting geminiviruses (10), the siRNAs detected were related to both geminiviral components (A and B) and a major hybridization signal was obtained with probes that included the PepGMV DNA A intergenic region (Fig. 5). These observations open the possibility that geminiviruses could use a PTGSbased strategy as a mechanism to differentially regulate the expression of its genes in terms of time and space. This PTGSbased viral regulation hypothesis will have to be tested experimentally.

\section{ACKNOWLEDGMENTS}

We thank H. Morales-López for his invaluable collaboration in the designing and construction of the low-pressure, handheld inoculation device; H. Shimada-Beltrán and J. Vega-Arreguín for critical reading of the manuscript; and E. A. Rodríguez-Negrete for helpful discussions. We acknowledge support from Conacyt-México to J. Carillo-Tripp (Ph.D. fellowship) and to R. F. Rivera-Bustamante (Research Grant ConacytSagarpa 2004-115).

\section{LITERATURE CITED}

1. Anandalakshmi, R., Pruss, G. J., Ge, X., Marathe, R., Mallory, A. C., Smith, T. H., and Vance, V. B. 1998. A viral suppressor of gene silencing in plants. Proc. Natl. Acad. Sci. USA 95:13079-13084.

2. Anaya-López, J. L., Torres-Pacheco, I., González-Chavira, M., Garzón-Tiznado, J. A., Pons-Hernández, J. L., Guevara-González, R. G., Muñoz-Sánchez, C. I., Guevara-Olvera, L., Rivera-Bustamante, R. F., and Hernández-Verdugo, S. 2003. Resistance to geminivirus mixed infections in Mexican wild peppers. Hort. Sci. 38:251-255.

3. Asad, S., Haris, W. A. A., Bashir, A., Zafar, Y., Malik, K. A., Malik, N. N., and Lichtenstein, C. P. 2003. Transgenic tobacco expressing geminiviral RNAs are resistant to the serious viral pathogen causing cotton leaf curl disease. Arch. Virol. 148:2341-2352.

4. Baulcombe, D. 2004. RNA silencing in plants. Nature 431:356-363.

5. Bisaro, D. M. 2006. Silencing suppression by geminivirus proteins. Virology 344:158-168.

6. Bonilla-Ramírez, G. M., Guevara-González, R. G., Garzon-Tiznado, J. A., Ascencio-Ibañez, J. T., Torres-Pacheco, I., and Rivera-Bustamante, R. F. 1997. Analysis of the infectivity of monomeric clones of Pepper huasteco virus. J. Gen. Virol. 78:947-951.

7. Brigneti, G., Voinnet, O., Li, W. X., Ji, L. H., Ding, S. W., and Baulcombe, D. C. 1998. Viral pathogenicity determinants are suppressors of transgene silencing in Nicotiana benthamiana. EMBO J. 17:67396746.

8. Brown, J. K., Idris, A. M., Ostrow, K. M., Goldberg, N., French, R., and Stenger, D. C. 2005. Genetic and phenotypic variation of the Pepper golden mosaic virus complex. Phytopathology 95:1217-1224.

9. Carrillo-Tripp, J., Shimada-Beltrán, H., and Rivera-Bustamante, R. 2006. Use of geminiviral vectors for functional genomics. Curr. Opin. Plant Biol. 9:209-215.

10. Chellappan, P., Vanitharani, R., and Fauquet, C. M. 2004. Short interfering RNA accumulation correlates with host recovery in DNA virusinfected hosts, and gene silencing targets specific viral sequences. J. Virol. 78:7465-7477.

11. Covey, S. N., Al-Kaff, N. S., Langara, A., and Turner, D. S. 1997. Plants combat infection by gene silencing. Nature 385:781-782.

12. Dong, X. L., van Wezel, R., Stanley, J., and Hong, Y. G. 2003. Functional characterization of the nuclear localization signal for a suppressor of posttranscriptional gene silencing. J. Virol. 77:7026-7033.

13. Fauquet, C. M., Bisaro, D. M., Briddon, R. W., Brown, J. K., Harrison, B. D., Rybicki, E. P., Stenger, D. C., and Stanley, J. 2003. Revision of taxonomic criteria for species demarcation in the family Geminiviridae, and an updated list of begomovirus species. Arch. Virol. 148:405-421.

14. Fofana, I. B. F., Sangare, A., Collier, R., Taylor, C., and Fauquet, C. M. 2004. A geminivirus-induced gene silencing system for gene function validation in cassava. Plant Mol. Biol. 56:613-624.

15. Garzón-Tiznado, J. A., Torres-Pacheco, I., Ascencio-Ibañez, J. T., Herrera-Estrella, L., and Rivera-Bustamante, R. F. 1993. Inoculation of peppers with infectious clones of a new geminivirus by a biolistic procedure. Phytopathology 83:514-521.

16. Goldbach, R., Bucher, E., and Prins, M. 2003. Resistance mechanisms to plant viruses: an overview. Virus Res. 92:207-212.

17. Hamilton, A., Voinnet, O., Chappell, L., and Baulcombe, D. 2002. Two classes of short interfering RNA in RNA silencing. EMBO J. 21:46714679 . 
18. Hormuzdi, S. G., and Bisaro, D. M. 1995. Genetic analysis of Beet curly top virus: examination of the roles of L2 and L3 genes in viral pathogenesis. Virology 206:1044-1054.

19. Horns, T., and Jeske, H. 1991. Localization of Abutilon mosaic virus (AbMV) DNA within leaf tissue by in situ hybridization. Virology 181:580-588

20. Hutvágner, G., Mlynárová, L., and Nap, J. P. 2000. Detailed characterization of the posttranscriptional gene-silencing-related small RNA in a GUS gene-silenced tobacco. RNA 6:1445-1454.

21. Lindbo, J. A., Silva-Rosales, L., Proebsting, W. M., and Dougherty, W. G. 1993. Induction of highly specific antiviral state in transgenic plants: Implications for regulation of gene expression and virus resistance. Plant Cell 5:1749-1759.

22. Lucioli, A., Noris, E., Brunetti, A., Tavazza, R., Ruzza, V., Castillo, A. G., Bejarano, E. R., Accotto, G. P., and Tavazza, M. 2003. Tomato yellow leaf curl Sardinia virus Rep-derived resistance to homologous and heterologous geminiviruses occurs by different mechanisms and is overcome if virus-mediated transgene silencing is activated. J. Virol. 77:6785-6798.

23. Méndez-Lozano, J., Rivera-Bustamante, R. F., Fauquet, C. M., and De la Torre-Almaraz, R. 2001. Pepper huasteco virus and Pepper golden mosaic virus are geminiviruses affecting tomatillo (Physalis ixocarpa) crops in Mexico. Plant Dis. 85:1291.

24. Méndez-Lozano, J., Torres-Pacheco, I., Fauquet, C. M., and Rivera-Bustamante, R. F. 2003. Interactions between geminiviruses in a naturally occurring mixture: Pepper huasteco virus and Pepper golden mosaic virus. Phytopathology 93:270-277.

25. Mitter, N., Sulistyowati, E., and Dietzgen, R. G. 2003. Cucumber mosaic virus infection transiently breaks dsRNA-induced transgenic immunity to Potato virus $Y$ in tobacco. Mol. Plant-Microbe Interact. 16:936-944.

26. Muangsan, N., Beclin, C., Vaucheret, H., and Robertson, D. 2004. Geminivirus VIGS of endogenous genes requires SGS2/SDE1 and SGS3 and defines a new branch in the genetic pathway for silencing in plants. Plant J. 38:1004-1014.

27. Peele, C., Jordan, C. V., Muangsan, N., Turnage, M., Egelkrout, E., Eagle, P., Hanley-Bowdoin, L., and Robertson, D. 2001. Silencing of a meristematic gene using geminivirus-derived vectors. Plant J. 27:357-366.

28. Pooggin, M., and Hohn, T. 2004. Fighting geminiviruses by RNAi and vice versa. Plant Mol. Biol. 53:149-152.

29. Pooggin, M., Shivaprasad, P. V., Veluthambi, K., and Hohn, T. 2003. RNAi targeting of DNA virus in plants. Nat. Biotechnol. 21:131-132.

30. Preiss, W., and Jeske, H. 2003. Multitasking in replication is common among geminiviruses. J. Virol. 77:2972-2980.

31. Ratcliff, F., Harrison, B. D., and Baulcombe, D. C. 1997. A similarity between viral defense and gene silencing in plants. Science 276:1558-1560.

32. Rigden, J. E., Krake, L. R., Rezaian, M. A., and Dry, I. B. 1994. ORF C4 of tomato leaf curl geminivirus is a determinant of symptom severity. Virology 204:847-850.

33. Robertson, D. 2004. VIGS vectors for gene silencing: Many targets, many tools. Annu. Rev. Plant Biol. 55:495-519.

34. Roth, B. M., Pruss, G. J., and Vance, V. B. 2004. Plant viral suppressors of RNA silencing. Virus Res. 102:97-108.

35. Sambrook, J., Fritsch, E. F., and Maniatis, T. 1989. Molecular Cloning: A
Laboratory Manual. 2nd ed. Cold Spring Harbor Laboratory, Cold Spring Harbor, NY.

36. Stanley, J., Frischmuth, T., and Ellwood, S. 1990. Defective viral DNA ameliorates symptoms of geminivirus infection in transgenic plants. Proc. Natl. Acad. Sci. USA 87:6291-6295.

37. Stanley, J., and Townsend, R. 1985. Characterization of DNA forms associated with Cassava latent virus infection. Nucleic Acids Res. $13: 2189-2206$

38. Susi, P., Hohkuri, M., Wahlroos, T., and Kilby, N. J. 2004. Characteristics of RNA silencing in plants: Similarities and differences across kingdoms. Plant Mol. Biol. 54:157-174.

39. Torres-Pacheco, I., Garzón-Tiznado, J. A., Brown, J. K., Becerra-Flora, A., and Rivera-Bustamante, R. F. 1996. Detection and distribution of geminiviruses in Mexico and Southern United States. Phytopathology $86: 1186-1192$.

40. Turnage, M. A., Muangsan, N., Peele, C. G., and Robertson, D. 2002. Geminivirus-based vectors for gene silencing in Arabidopsis. Plant J. 30:107-114.

41. van den Boogaart, T., Maule, A. J., Davies, J. W., and Lomonossoff, G. P. 2004. Sources of target specificity associated with the recovery against Pea seed-borne mosaic virus infection mediated by RNA silencing in pea. Mol. Plant Pathol. 5:37-43.

42. van Wezel, R., Dong, X. L., Liu, H. T., Tien, P., Stanley, J., and Hong, Y. G. 2002. Mutation of three cysteine residues in Tomato yellow leaf curl virus-China $\mathrm{C} 2$ protein causes dysfunction in pathogenesis and posttranscriptional gene-silencing suppression. Mol. Plant-Microbe Interact. 15:203-208.

43. van Wezel, R., Liu, H., Tien, P., Stanley, J., and Hong, Y. 2001. Gene C2 of the monopartite geminivirus Tomato yellow leaf curl virus-China encodes a pathogenicity determinant that is localized in the nucleus. Mol. Plant-Microbe Interact. 14:1125-1128.

44. Vance, V., and Vaucheret, H. 2001. RNA silencing in plants--defense and counterdefense. Science 292:2277-2280.

45. Vanitharani, R., Chellappan, P., and Fauquet, C. M. 2005. Geminiviruses and RNA silencing. Trends Plant Sci. 10:144-151.

46. Vanitharani, R., Chellappan, P., Pita, J. S., and Fauquet, C. M. 2004. Differential roles of $\mathrm{AC} 2$ and $\mathrm{AC} 4$ of cassava geminiviruses in mediating synergism and suppression of posttranscriptional gene silencing. J. Virol. 78:9487-9498.

47. Voinnet, O. 2001. RNA silencing as a plant immune system against viruses. Trends Genet. 17:449-459.

48. Voinnet, O., Lederer, C., and Baulcombe, D. C. 2000. A viral movement protein prevents spread of the gene silencing signal in Nicotiana benthamiana. Cell 103:157-167.

49. Voinnet, O., Pinto, Y. M., and Baulcombe, D. C. 1999. Suppression of gene silencing: A general strategy used by diverse DNA and RNA viruses of plants. Proc. Natl. Acad. Sci. USA 96:14147-14152.

50. Wilson, T. M. A. 1993. Strategies to protect crop plants against viruses: Pathogen-derived resistance blossoms. Proc. Natl. Acad. Sci. USA 90:3134-3141.

51. Xin, H. W., and Ding, S. W. 2003. Identification and molecular characterization of a naturally occurring RNA virus mutant defective in the initiation of host recovery. Virology 317:253-262. 